\title{
The Knoll-Concept to Decrease the Prevalence of Parkinson's Disease
}

\author{
Ildikó Miklya \\ Semmelweis University, Department of Pharmacology and Pharmacotherapy \\ Hungary
}

\section{Introduction}

(-)-Deprenyl (D)/Selegiline, introduced under the code name: E-250, in 1964/65 as a new spectrum "psychic energizer" (Knoll et al., 1965), and named (-)-deprenyl from 1970, became famous in 1971/1972 as the first selective inhibitor of B-type monoamine oxidase (MAO-B) (Knoll \& Magyar, 1972). D, registered at present in 64 countries, started its world-wide carrier as a therapeutic agent in 1977 as the unique MAO inhibitor free of the cheese-effect (reviewing its early history see Knoll, 1983).

In the early 1960s when Knoll developed D MAO inhibitors were at the center of interest. It was the period when the hypothesis that depression is associated with diminished monoaminergic tone in the brain took root in the scientific community. MAO inhibitors played a key role in the development of this hypothesis. It became clear that MAO inhibitors elated depressed patients because they enhance the biological activity of monoamine transmitters in the central nervous system.

In 1951 isoniazid and its isopropyl-derivative, iproniazid, were successfully introduced for the treatment of tuberculosis and it was an unexpected observation that in contrast to isoniazid, iproniazid produced undesirable central stimulation in some patients. Zeller, who proposed in 1938 the name "monoamine oxidase" for the class of enzymes responsible for the oxidative deamination of monoamines, discovered in 1952 that iproniazid is capable to inhibit MAO activity in the brain and isoniazid is devoid of this property (Zeller \& Barsky, 1952). In 1956 Crane analyzed the psychiatric side effects of iproniazid and concluded that it might be beneficial in the treatment of depression (Crane, 1956) and Kline introduced it as a "psychic energizer" (Kline, 1958).

Series of new MAO inhibitors were soon developed. It was, however, observed in 1963 that after eating cheese depressive patients treated with the highly potent MAO inhibitor, tranylcypromine, develop temporary clinical symptoms similar to a paroxysm induced by pheochromocytoma: hypertension, palpitation, neck stiffness, headache, nausea, vomiting. The same was observed also during treatment with nialamid, pargyline, and other MAO inhibitors. Blackwell (1963) realized that the hypertensive crisis is associated with the ingestion of high amounts of tyramine in cheese, the metabolism of which is inhibited by the MAO inhibitors ("cheese-effect"). Similar clinical episodes have also been observed after the ingestion of some other foodstuffs, such as yeast products and chianti wines, pickled herring, chicken liver, which are rich in tyramine, and/or other amine such as $\beta$-phenylethylamine (PEA), tryptamine, or L-3,4-dihydroxyphenylalanine (L-DOPA). 
Knoll et al. demonstrated in a paper published in 1968 that the new MAO inhibitor, E-250, is free of the cheese-effect, because in contrary to the known MAO inhibitors, it does not potentiate, but inhibits the effect of tyramine (Knoll et al., 1968). The summary of this paper concluded that: "As the so-called cheese reaction, namely clinical symptoms similar to a paroxism induced by pheochromocytoma after cheese consumption is caused by the tyramine potentiating action of the MAO inhibitors, this tyramine inhibiting property of E-250 may be highly valuable for human therapy." Following Knoll's proposal it was shown later that D is free of the cheese effect also in humans (Elsworth et al., 1978; Sandler et al., 1978).

It was Birkmayer in Vienna who first demonstrated that, in contrast to the known MAO inhibitors, D can be combined safely with levodopa in Parkinson's disease (PD). Because of the serious side effect of levodopa in PD, Birkmayer and Hornykiewicz tried earlier to achieve a levodopa-sparing effect by the concurrent administration of levodopa and an MAO inhibitor, but this line of clinical research was soon terminated because the combination elicited serious hypertensive attacks (Birkmayer \& Hornykiewicz, 1962). Birkmayer, considering the peculiar pharmacological profile of D dared to combine this MAO inhibitor with levodopa in PD and since the levodopa-sparing effect was achieved without side-effect (Birkmayer et al., 1977), this study initiated, and the Lancet Editorial "Deprenyl in Parkinson's disease" (The Lancet, September 25, 1982) substantially promoted the worldwide use of D in PD. Further studies revealed that $\mathrm{D}$ slows the rate of the functional deterioration of the nigrostriatal dopaminergic neurons in patients with early, untreated PD, and thus slows the progress of the disease (Tetrud \& Langstone, 1989; Parkinson Study Group, 1989, 1993; Allain et al., 1991; Myttyla et al., 1992; Larsen et al., 1999).

The first two studies to demonstrate the beneficial effect of D in Alzheimer's disease (AD) were published in 1987 (Martini et al., 1987; Tariot et al., 1987) and a stream of clinical studies with small sample sizes, published between 1990 and 1993, confirmed the usefulness of D in the treatment of the disease (for review see Knoll, 2001). Finally, in 1977 a proper controlled trial showed that in patient with moderately severe $\mathrm{AD}$, treatment with $\mathrm{D}$ slows the progression of the disease (Sano et al., 1997).

In retrospect it is hard to understand why D was before 2006, thus for 40 years, in striking contrast with the expectation of its developer, nowhere in the world registered with the indication to use it as an antidepressant. Knoll selected E-250 for further development in the hope that it will be used as a new efficient antidepressant. Before publishing the first paper on E-250 he already asked his schoolmate, the psychiatrist Ervin Varga, to test the new compound in depressed patients. The outcome of this preliminary study was cited as personal communication in the first paper (Knoll et al., 1965). Varga presented his results in the same year in a lecture (Varga, 1965) and published with his coworkers two papers on the antidepressant effect of D (Varga \& Tringer, 1967; Tringer et al., 1971). Further clinical studies confirmed the antidepressant effect of D (Mann \& Gershon, 1980; Youdim, 1980; Tom \& Cummings, 1998; Zesiewitz et al., 1999; Miyoshi, 2001) and an analysis of the use of $\mathrm{D}$ in major depression was carefully reviewed (Gaszner \& Miklya, 2006), nevertheless, only 40 years after Knoll's original proposal in 2006 was a D preparation (Emsam), based on a double-blind placebo-controlled trial performed by Amsterdam (2003), registered in the USA for the treatment of major depression. Emsam is the first transdermally administered antidepressant.

Slowing the age-related deterioration of the catecholaminergic neurons is that still unexploited pharmacological property of $\mathrm{D}$ which deserves from practical point of view 
favored attention. Although liquid deprenyl citrate preparations (Selepryl, Cyprenil) containing $1 \mathrm{mg} \mathrm{D}$ in 1 drop, the proposed daily dose for slowing brain aging, are since years in circulation, a controlled, double-blind clinical trial to lay the firm foundation of the prophylactic antiaging D therapy remained up to the present unperformed.

Since the estimated increase of the number of individuals over 65 will reach by 2050 the 1.1 billion level, thus to decrease the prevalence of age-related neurodegenerative diseases, like Parkinson's and Alzheimer's, is an urgent necessity, the main aim of this review is to sum up the arguments which renders probable the concept that the prophylactic lifelong daily administration of $1 \mathrm{mg} \mathrm{D}$ from sexual maturity until death improves the quality of life in senescence and show promise to prevent or delay the onset of PD and AD (Knoll, 2005).

\section{The development of deprenyl}

Joseph Knoll developed D in the early 1960s. Since 1951 he performed with his two coworkers, Karoly Kelemen and Berta Knoll, behavioral studies with rats, the aim of which was to study the cortical mechanisms which ensure the manipulability of the individual. He essentially developed in those years his working hypothesis that the appearance of the mammalian brain with the ability to acquire drives produced species with manipulability to fit for domestic life, i.e. to life in intimate association with and to the advantage of humans. To study the nature of the acquired drives, a special model was developed, the training of rats in a way that they fix in their cortex an unnatural urge, the so-called glass-cylinderseeking drive. Those rats that performed best acquired this drive in a stable manner and maintained this unnatural urge for a life time. Knoll summarized the results and described the conclusion of his first 16-year research period with the glass-cylinder-seeking rats in a monograph (Knoll, 1969) and finally presented, after a further 36-year research period, his theory "The Brain and Its Self. A Neurochemical Concept of the Innate and Acquired Drives" in a second monograph (Knoll, 2005). His theory, based on the physiology of the acquired drives, furnishes knowledge about the most important brain mechanisms which created the society: the manipulability of the cortex.

An acquired drive is always built on an inner drive, however, after the acquired drive has been ultimately fixed, its origin, the innate drive, cannot be recognized anymore either in man or a domesticated animal. A glass-cylinder-seeking rat will never acquire this drive under natural conditions. The experimenter manipulated consciously its brain, making use of the innate potential to change a group of cortical neurons via proper training in a way that the rat is fixing an acquired drive. In case of a fully successful training, the glasscylinder-seeking rat behaves as one who has a fanatical desire for the glass-cylinder. These rats showed the same high-grade adaptability and readiness in overcoming different obstacles during goal-attainment as the ones influenced by innate drives, such as hunger or sexual desire. "Humans possess the most manipulable brain among all living creatures on earth. The brain of a suicide-killer is furtively manipulated. The properly acquired drive develops as a result of long-lasting training. The subject always acts under coercion, under severe mental pressure. Nevertheless, it is the nature of acquired drives that if the manipulation was fully successful the individual ultimately behaves as one possessing a fanatical desire to reach the acquired-drive-motivated goal." (Knoll, 2005, p 139).

It was at the beginning of these behavioral studies that the need for a new type central stimulant, a proper experimental tool for studying the physiology of the acquired drives, emerged. Knoll's aim was to find an amphetamine-like psychic energizer without the side- 
effect of the amphetamines that as soon as the dose is surpassing the $1-2 \mathrm{mg} / \mathrm{kg}$ level, the drug-induced continuous, irresistible release of catecholamines from their intraneuronal stores in the brain stem neurons arrives to an intensity resulting in aimless hypermotility which blocks purposeful behavior. Since in those times the MAO inhibitors represented a new type of central stimulants, he decided to approach his goal via a structure-activityrelationship study, the starting structure of which was methamphetamine, containing, in order to make the molecule capable to block MAO activity irreversibly, a propargyl-group attached to the nitrogen.

Out of a series of newly synthesized patentable propargyl-group-containing methamphetamine-derivatives Knoll selected finally E-250 for further development. Amphetamines, the synthetic long acting analogues of PEA are like their parent compound releasers of noradrenaline from their intraneuronal stores, thus they increase blood pressure. E-250 behaved anomalously. It did not increase blood pressure; it even inhibited the blood pressure increasing effect of its parent compound (see Knoll et al., 1965, Fig.1). Knoll realized the peculiar practical importance of this behavior and demonstrated that this compound, in contrast to all known MAO inhibitors, does not potentiate, but inhibits the effect of tyramine, thus it is free of the cheese effect (Knoll et al., 1968). This feature of D allowed later to combine it safely with levodopa in PD and initiated its world-wide use as a therapeutic agent (Birkmayer et al., 1977).

\section{The period while the selective inhibition of MAO-B in the brain was thought to be fully responsible for the therapeutic effects of deprenyl}

In the same year when Knoll demonstrated with two of his coworkers that D is free of the cheese-effect (Knoll et al., 1968), Johnston described a new irreversible MAO inhibitor, MB 9302 (later named clorgyline), which preferentially inhibited the deamination of serotonin (Johnston, 1968). Johnston proposed the existence of two forms of MAO, "type A" and "type $\mathrm{B}^{\prime \prime}$, the former being selectively inhibited by clorgyline and the latter insensitive to it. This nomenclature has become widely accepted and is still in use. The unique substrate specificity of this new MAO inhibitor was soon corroborated (Hall et al., 1969), and clorgyline became the classic experimental tool to inhibit selectively MAO-A.

In MAO research a selective inhibitor of MAO-B was badly needed and Knoll realized that $\mathrm{D}$ was the missing link, the highly selective inhibitor of MAO-B. He presented this finding first in 1971 in his lecture at the first international MAO meeting in Cagliari (Sardinia). D was used thereafter as the specific experimental tool to analyze MAO-B. The first paper which described this novel property of D (Knoll \& Magyar, 1972) became 10 years later a citation classic (Knoll J., This Week's Citation Classic, January 15, 1982). After the discovery that $\mathrm{D}$ is a selective inhibitor of MAO-B this property of the compound remained for years in the center of his interest. He pointed for the first time in his lecture at the second international MAO meeting "Monoamine Oxidase and its Inhibition" organized by the CIBA Foundation in London 1975, to the importance to study carefully the consequence of the relation between PEA and D.

Since PEA, the physiologically important endogenous central nervous system stimulant is a specific substrate for MAO-B, thus D is increasing exceedingly PEA levels in the brain, he mentioned in the summary of this lecture that D in combination with PEA might be efficient in certain types of depression. In the discussion of his lecture (Knoll, 1976, pp 155-160) he referred repeatedly to the importance of this line of further research. A couple of years later, 
following Knoll's proposal, the antidepressive efficacy of D (5-10 mg daily) plus phenylalanine $(250 \mathrm{mg} /$ day), the precursor of PEA, has been evaluated in 155 unipolar depressed patients. Both oral and intravenous administration of the combination showed beneficial effect in $90 \%$ of outpatients and $80.5 \%$ of inpatients. It was concluded that this combined treatment has a potent antidepressive action based on the accumulation of PEA in the brain (Birkmayer et al., 1984).

In a further study Knoll enlarged his concept that D offers a previously unknown possibility to exploit the natural endowments of PEA and argued as follows (see Knoll, 1978a, p.59):"...a progressive significant decrease in the dopamine content of the nigrostriatum is to be observed at the decline of life....The physiological decrease of the dopamine content of the striatum could easily be prevented by the continuous administration of a small dose of (-)-deprenyl....", moreover: "There is now ample evidence that phenylethylamine is endogenous in the brain and might play a role in affective behavior. Urinary excretion of free phenylethylamine was found to be reduced in depressed patients supporting the hypothesis that phenylethylamine deficit may be one of the biochemical lesions in depression...".

In the same year, in another lecture (Knoll, 1978b) he emphasized the importance to begin the administration of D in the earliest state of parkinsonism. The validity of Knoll's proposal to begin the administration of this drug in the earliest state of PD got splendid verification a decade later in the Deprenyl and Tocopherol Antioxidant Therapy of Parkinsonism (DATATOP) study performed on selected patients with early untreated PD. It was shown that the administration of $\mathrm{D}$ delays significantly the onset of disability necessitating levodopa therapy (Tetrud \& Langston, 1989; Parkinson Study Group, 1989). Knoll's close reasoning in this time was as follows: "Considering the mechanism of action of (-)-deprenyl it seems to be of high importance to begin the administration of this drug in the earliest state of parkinsonism, in order to preserve as far as possible the physiological control of acetylcholine release in the striatum thereby reducing the amount of the required levodopa to the lowest possible level. Even the known slow degradation of the nigrostriatal dopaminergic neurons, a frequent phenomenon of ageing, might be counteracted by starting long term treatment with low doses of (-)-deprenyl in due time." (Knoll, 1978b, p 195).

Furthermore, it is evident from the discussion quoted from this study that the concept to slow the physiological age-related decline of the dopaminergic machinery in the brain stem via prophylactic low dose D treatment, took slowly its final shape, and we may say in retrospect that Knoll's coming important longevity studies (Knoll, 1988; Knoll et al., 1989, 1994) cast in this paper their shadows before.

We can also follow in these years Knoll's method that whenever he wanted to prove undeniably the relevance of a well defined pharmacological effect of D in its therapeutic efficiency he started a structure-activity-relationship study and fabricated a D-derivative which differed only in its pharmacological spectrum from its parent compound in being devoid of the questionable property. For example, he found that $\mathrm{D}$ is a potent inhibitor of the uptake of amines into the nerve endings of catecholaminergic neurons.

Since he wanted to test the significance of the monoamine-uptake inhibitory property of D in its therapeutic effect, he developed selective MAO-B inhibitors, J-508 and U-1424, devoid of this effect (Knoll et al., 1978c). Using N-methyl-N-propargyl-/1-indenyl/-ammonium (J-508) as a reference compound which acts as a highly potent MAO inhibitor, devoid of uptake-inhibitory and releasing effects, the influence of MAO inhibitors on uptake was 
tested on a battery of isolated organs (cat nictitating membrane, perfused ear artery and strip of pulmonal artery of the rabbit, rat vas deferens).

In contrast to the nonselective and A-selective MAO inhibitors, as well as to the newly introduced selective MAO-B inhibitors (J-508, U-1424), D was unique in inhibiting tyramineuptake. This means that $\mathrm{D}$ is unique in being free of the cheese effect. This was for example the reason why Knoll did not suggest developing J-508 as a therapeutic agent, despite that this compound was found to be a 20-times more potent selective inhibitor of MAO-B than D (Knoll, 1978c, Table 2).

It is remarkable in this context that, about 30 years later, the desmethyl-analogue of J-508 (Rasagiline) was registered as a "new" second generation selective MAO-B inhibitor with the argument that since (-)-methamphetamine is a metabolite of D of which rasagiline is free, this is the advantage of rasagiline over D. Everybody who reads the literature knows that this is a sham-argument in support of a "me too" compound. An exact experimental study (Yasar et al. 1993) proved that D is free of amphetamine-like dependence capacity, they concluded:"...the preclinical findings reviewed generally support the clinical experience that in over 20 years of therapeutic use there has been no established case of human abuse l-deprenyl." (Yasar et al., 1993, p 230). Furthermore, it is absolutely out of the common that there is nowhere the slightest hint in the rapidly increasing rasagiline literature that since this compound is the desmethyl-analogue of J-508, the pharmacology of which was described in detail 30 years ago, the developers carefully compared the pharmacological spectrum of rasagiline and J-508 showing its advantage over its parent compound. Since J-508 is devoid of the catecholaminergic activity enhancer (CAE) effect characteristic to $\mathrm{D}$, we tested in this respect rasagiline in the shuttle box and found that this J-508 analogue bears resemblance to its parent compound and not to D (Miklya, 2008).

Influenced by new experimental data Knoll became suspicious that an unknown stimulatory effect and not MAO-B inhibition might primarily be responsible for the therapeutic benefits of the drug. By changing the propargyl moiety, which binds covalently with the flavin in $\mathrm{MAO}$, to a propyl group, he developed 1-phenyl-2-propylamino-pentane (PPAP), a Danalogue, free of MAO-B inhibitory potency (Knoll et al., 1992a). He described in his monograph (Knoll, 2005) the essence of the PPAP story as follows: "With the development of (-)-1-phenyl-2-propylaminopentane, (-)-PPAP, the (-)-deprenyl analogue free of the MAO$\mathrm{B}$ inhibitory potency, we already furnished direct evidence that the enhanced dopaminergic activity following administration of (-)-deprenyl was unrelated to the inhibition of MAO-B. Because (-)-PPAP, like (-)-deprenyl, inhibited the uptake of tyramine in isolated smooth muscle tests, we first assumed that the drug-induced enhanced dopaminergic activity was due to an uptake inhibitory effect. Further studies revealed that this interpretation was false." The discovery of the CAE effect in the early 1990s clarified the main mechanism through which $\mathrm{D}$ is enhancing the activity of the nigrostriatal dopaminergic neurons and terminated the period when the selective inhibition of MAO-B was in the center of interest.

\section{Longevity studies. The proof that lifelong administration of deprenyl slows significantly the age-related decline of sexual performance and learning ability and prolongs life}

The first paper which furnished experimental evidence for the pressing necessity to start a longevity study is the one entitled "Can the suicide inactivation of MAO by deprenyl explain its pharmacological effects?" (Knoll, 1981a). In this paper the pharmacological 
spectrum of D was reviewed and experimental and clinical evidence was listed proving that $\mathrm{D}$ facilitates via different mechanisms the dopaminergic modulation in the brain. The putative physiological role of extrasynaptosomal MAO, which is of the B-type, in the dopaminergic and "trace aminergic" modulation and its significance in the therapeutic effect of D was analyzed. The working hypothesis was proposed that the age-related increase in MAO-B activity in the human brain is the biochemical lesion in senescence which results in a decline of dopaminergic and "trace aminergic" modulation and triggers many of the phenomena (slight parkinsonian syndrome, anxiety, depressed mood, severely inhibited sexual performance, etc.) known to accompany the aging process. The obvious possibility to prevent or counteract the MAO-B related consequences of aging by long-term treatment with $\mathrm{D}$ was discussed. It was shown in this paper first that $\mathrm{D}$ is significantly improving the sexual performance of sluggish male rats and clorgyline is devoid of this property. The aphrodisiac effect of D in aged sluggish male rats was further demonstrated in a couple of papers (Knoll, 1981b; Yen et al., 1982; Knoll et al., 1983).

Knoll presented his fully elaborated strategy to improve the quality of life in senescence via the prophylactic life-long administration of D in his lecture delivered at the "Strategy of Drug Research" IUPAC-IUPHAR Symposium in Nordwijkerhout (The Netherlands) in 1981. He summarized his views as follows: "In the aging brain, there is a loss of neurons compensated for by a proliferation of glial cells. We might thus predict that dopaminergic and "trace aminergic" modulation in the brain declines in senescence because of loss of neurons and because of the increased monoamine oxidase (MAO)-B activity present in the glia. The hypothesis was forwarded that the significant increase of the incidence of depression in the elderly, the age-dependent decline in male sexual vigor and the frequent appearance of parkinsonian symptoms in the latter decades of life might be attributed to a decrease of dopamine and "trace amines" in the brain. The possibility to counteract these biochemical lesions of aging by chronic administration of (-)-deprenyl, a selective inhibitor of MAO-B, which facilitates dopaminergic and "trace aminergic" activity in the brain and is a safe drug in man, was analyzed in detail. The restitution and long term maintenance of full scale sexual activity in aged male rats continuously treated with (-)-deprenyl was demonstrated as an experimental model in support of the view that the long term administration of small doses of deprenyl may improve the quality of life in senescence" (Knoll, 1982, p 107).

In one of his following studies "Deprenyl (selegiline): the history of its development and pharmacological action" (Knoll, 1983), he reviewed experimental and clinical data to show the potential benefits of using $\mathrm{D}$ in the elderly. He referred for example to a paper which showed that D significantly prolonged the duration of PD, i.e. the lifespan of the D-treated patients was substantially extended (Birkmayer, Knoll et al., 1983). Knoll's hypothesis inspired this clinical analysis and led later to a more extensive analysis of Birkmayer's clinical data which definitely showed increased life expectancy resulting from addition of D to Madopar-treatment in PD (Birkmayer, Knoll et al., 1985).

In 1983 Knoll introduced his concept regarding the peculiar antiaging effect of D to the gerontologists in a lecture presented at the $7^{\text {th }}$ European Symposium on Basic Research in Gerontology (Budapest, Hungary). He presented in this lecture new data to demonstrate that since the dopaminergic system represents the most rapidly aging neuronal network in the human brain, we lose after age 45 about $13 \%$ of our dopamine per decade, and D facilitates without side effects in a unique manner dopaminergic activity, which plays a 
leading role in the age-related decline of learning ability and sexual potency, it is reasonable to try to improve the quality of life in senescence via the prophylactic life-long small-dose administration of D (Knoll, 1985).

Knoll performed on a special, long-living strain of rats (first generation Wistar males $\mathrm{x}$ Logan females), with his two coworkers, Dallo and Yen, his first longevity study between 1984 and 1988. The concept and teaching of this study was published in a crucially important paper (Knoll, 1988) and in a brief summary (Knoll et al., 1989).

The study revealed that better performers in the mating test are better learners in the shuttle box and the more active animals live significantly longer than their less active peers. It was established by the aid of $\mathrm{D}$ which increased superoxide dismutase activity in the striatum, facilitated the activity of the nigrostriatal dopaminergic neurons with utmost selectivity, and protected these neurons from their age-related decay, that the efficiency of a rat in behavioral test, as well as the duration of its life are striatal dopamine dependent functions.

As a measure of striatal function, sexual activity was tested once a week in a group of male rats $(n=132)$ from $24^{\text {th }}$ month of their life. Because of the age-related decay of this function none of the 2-year-old animals displayed full scale sexual activity. By dividing the group equally the rats were treated with saline and $D(0.25 \mathrm{mg} / \mathrm{kg} \mathrm{sc}$.$) , respectively, three times a$ week. In the saline-treated group $(n=66)$ the last signs of sexual activity vanished to the $33^{\text {rd }}$ week of treatment. D-treatment restored full scale sexual activity in 64 out of 66 rats. The longest living rat in the saline-treated group lived 164 weeks. The average lifespan of the group was $147.05 \pm 0.56$ weeks. The shortest living animal in the D-treated group lived 171 weeks and the longest living rat died during the $226^{\text {th }}$ week of its life. The average lifespan was $197.98 \pm 2.36$ weeks, i.e. higher than the estimated maximum age of death in the rat (182 weeks). This was the first instance that by the aid of a well-aimed medication, members of a species lived beyond the known lifespan maximum. Further detailed studies in Knoll's laboratory corroborated the results of the first longevity study. It was demonstrated that rats treated during their post-developmental phase of life with a small dose of D lost their ability to ejaculate later (Knoll et al., 1989; Knoll, 1992; Knoll et al., 1994), showed a slower decline in learning performance with the passing of time (Knoll, 1989; Knoll et al., 1989, 1994), and lived significantly longer than their saline-treated peers (Knoll et al., 1989, 1994).

The original finding that D prolongs life was confirmed in rats (Milgram et al., 1990; Kitani et al., 1993), mice (Yen \& Knoll, 1992; Freisleben et al., 1994; Archer et al., 1996), hamsters (Stoll et al., 1997), and dogs (Ruehl et al., 1997). In one strain of mice D-treatment had no beneficial effect on survival (Ingram et al., 1993); and Stoll et al. (1997) found increased lifespan in D-treated female hamsters only. Moreover, in the longevity studies substantial strain differences were found in the efficiency of D. It has to be considered, however, that enhancer substances stimulate the enhancer-sensitive neurons in the brain stem in a peculiar manner. Thus, the same dose of an enhancer drug may exert a peak effect on one strain, a much lower effect on an other strain, and be ineffective on a third strain (see Main Heading 5 for details).

One group found, in striking contrast with all other studies, an increased mortality in male Wistar rats treated with D $0.5 \mathrm{mg} / \mathrm{kg}$ for up to 20 months (Gallagher et al., 1998). The toxicological studies performed with $\mathrm{D}$ and decades of experiences on thousands of rats make clear that the administration of D $0.5 \mathrm{mg} / \mathrm{kg} 3$ times a week could not be responsible for the observed increased mortality in the rats. It is worth mentioning that even in clinical studies improper combination of levodopa with $\mathrm{D}$ led to confusion and misinterpretation as 
it happened in a study performed by the Parkinson's Disease Research Group of the United Kingdom and published in 1995 (Lees, 1995; for a critical analysis see Knoll, 1998).

\section{The catecholaminergic activity enhancer (CAE) effect of deprenyl}

The availability of HPLC to measure exactly the catecholamines and serotonin in physiological quantities allowed a new approach. The thorough analysis of the dosedependent effect of D on the release of catecholamines and serotonin from isolated, discrete, rat brain regions (dopamine from the striatum, substantia nigra and tuberculum olfactorium; noradrenaline from the locus coeruleus; and serotonin from the raphe) pointed to operation of a previously unknown peculiar enhancer regulation in the catecholaminergic neurons in the brain stem.

Rats were treated with $0.01,0.025,0.05,0.1$ and $0.25 \mathrm{mg} / \mathrm{kg} \mathrm{D}$, respectively, once daily for 21 days. Discrete rat brain regions were isolated 24 hours after the last injection and the biogenic amines released during $20 \mathrm{~min}$ from the freshly isolated tissue samples were measured. The amount of dopamine released from the substantia nigra and tuberculum olfactorium clarified that the dopaminergic neurons worked on a significantly higher activity level even in rats treated with the lowest, $0.01 \mathrm{mg} / \mathrm{kg}$ dose of $\mathrm{D}$. As this small dose of D leaves the MAO-B activity and the uptake of amines practically unchanged, this study was the first unequivocal demonstration for the operation of a hitherto unknown enhancer mechanism in dopaminergic neurons stimulated by D in very low doses (Knoll \& Miklya, 1994). D enhanced also the release of noradrenaline from the locus coeruleus, but did not enhance, even diminished the release of serotonin from the raphe. Thus, D proved to exert a highly specific, previously undetected CAE effect.

Further studies revealed that the parent compounds of D, PEA and methamphetamine, are primarily CAE substances but this property remained undetected because PEA and its long acting derivatives, amphetamine and methamphetamine, induce the continuous release of catecholaminergic transmitters from their neuronal pool which hinders completely the detectability of the CAE effect of these compounds. Since D is the only PEA-derived CAEsubstance which is devoid of the catecholamine releasing property, it enabled to discover the enhancer regulation in the catecholaminergic neurons of the brain stem (Knoll et al., 1996a,b). An additional proof of the operation of the enhancer regulation in the brain stem was the discovery that tryptamine is a natural enhancer substance which acts primarily on the serotonergic neurons (Knoll, 1994, for review see Knoll, 2005, 3.1.1). This experience catalyzed later the structure-activity-relationship study aiming to develop a tryptaminederived enhancer substance and led finally to the selection of R-(-)-1-(benzofuran-2-yl)-2propylaminopentane (BPAP), which is in rat experiments about hundred times more potent than D, for further development (Knoll et al., 1999). In contrast to D which is almost ineffective on the serotonergic neurons, BPAP is a highly potent enhancer of the serotonergic neurons.

Fig.1 and 2a,b show the striking difference between the catecholamine-releasing and the CAE effect.

The enhancer substances stimulate the enhancer sensitive neurons in the brain stem in a peculiar manner. Fig.3 shows, as an example, the bi-modal, bell-shaped concentration curve characteristic to the enhancer effect of BPAP, the presently known most potent and selective enhancer substance. The one in the low nanomolar range, with a peak effect at $10^{-13} \mathrm{M}$ concentration, clearly demonstrates the existence of a highly complex, specific form of 
enhancer regulation in noradrenergic neurons. The second, with a peak effect at $10^{-6} \mathrm{M}$ concentration, shows the operation of a ten million times less sensitive, obviously nonspecific form of the enhancer regulation in these neurons (Knoll et al., 2002).

\section{Deprenyl-induced enhancement of scavenger function in the striatum}

Knoll brought up for the first time in 1987 his idea that D may facilitate scavenger function in striatal neurons (Knoll, 1987). In a section of this paper, entitled "The putative role of scavenger function changes in the long-term deprenyl treatment induced protection of the nigrostriatal dopaminergic neuron", he referred to their experiences that the physiological consequences of the dopaminergic regulation in the caudate nucleus are detectable by measuring the basal ouabain-stimulated release of acetylcholine (ACh) (Knoll, 1978c).

Dopamine cell bodies dominating in the A9 and A10 of the substantia nigra produce such large amounts of dopamine that the striatum, in which neurons terminate, contains the highest amount of dopamine in the brain. The physiological role of dopamine released in the striatum is the continuous inhibition of the release of ACh from the cholinergic interneurons of the caudate nucleus. According to data shown in this paper (Knoll, 1987, Table 6) the amount of ouabain-induced release of ACh from isolated striatal slices dissected from untreated rats was found to be $366.7 \pm 57.3 \mathrm{pmole} / \mathrm{g} / \mathrm{min}$ and the addition of dopamine $\left(2.6 \times 10^{-4} \mathrm{~mole} / \mathrm{L}\right)$ increased the amount to $591.0 \pm 52.5 \mathrm{pmole} / \mathrm{g} / \mathrm{min}$, showing that dopamine stimulated the presynaptic dopamine "autoreceptors". In striatal slices taken from rats pretreated with 6-hydroxydopamine (6-OHDA) the ouabain-induced release of ACh increased to $706.0 \pm 60.0 \mathrm{pmole} / \mathrm{g} / \mathrm{min}$, similarly to the situation in PD, where loss of the nigrostriatal dopaminergic neurons leads to an uninhibited release of $\mathrm{ACh}$ in the

\section{3 min $\quad \alpha$ electric stimulation}

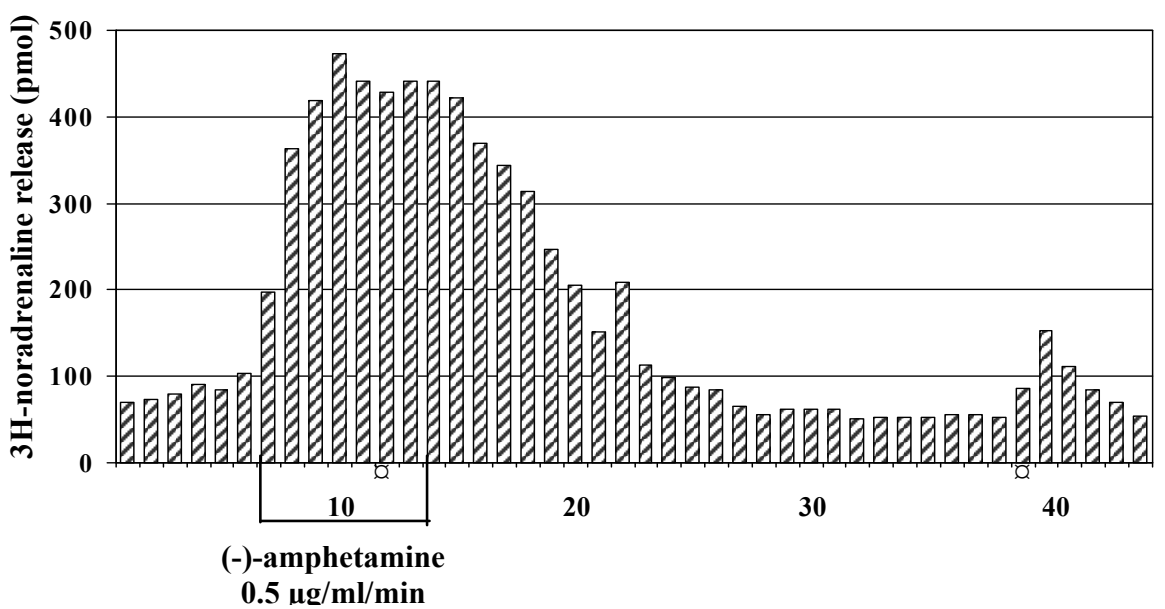

Fig. 1. Demonstration that amphetamine, the synthetic PEA-derivative, is inducing a long lasting spontaneous release of ${ }^{3}[\mathrm{H}]$-noradrenaline from an isolated rat brain stem and electrical stimulation is ineffective, showing that the detectability of the enhancer effect is hindered. 
striatum. The addition of dopamine inhibited to $372.9 \pm 93.8 \mathrm{pmole} / \mathrm{g} / \mathrm{min}$ the ouabaininduced release of $\mathrm{ACh}$, thus acted in the model like levodopa acts in PD.

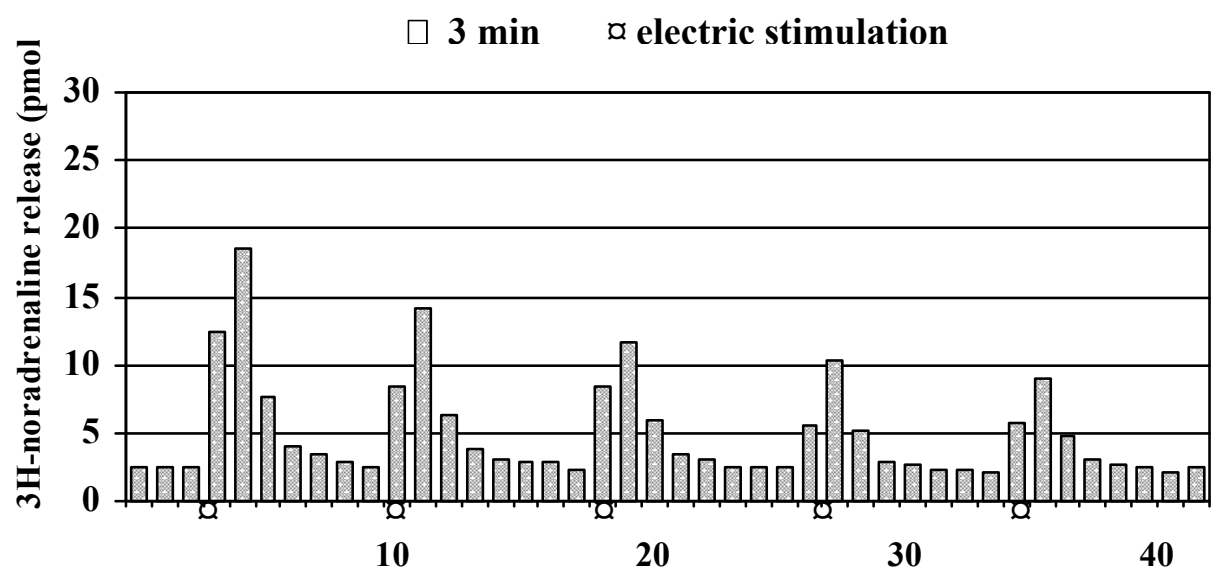

(a)

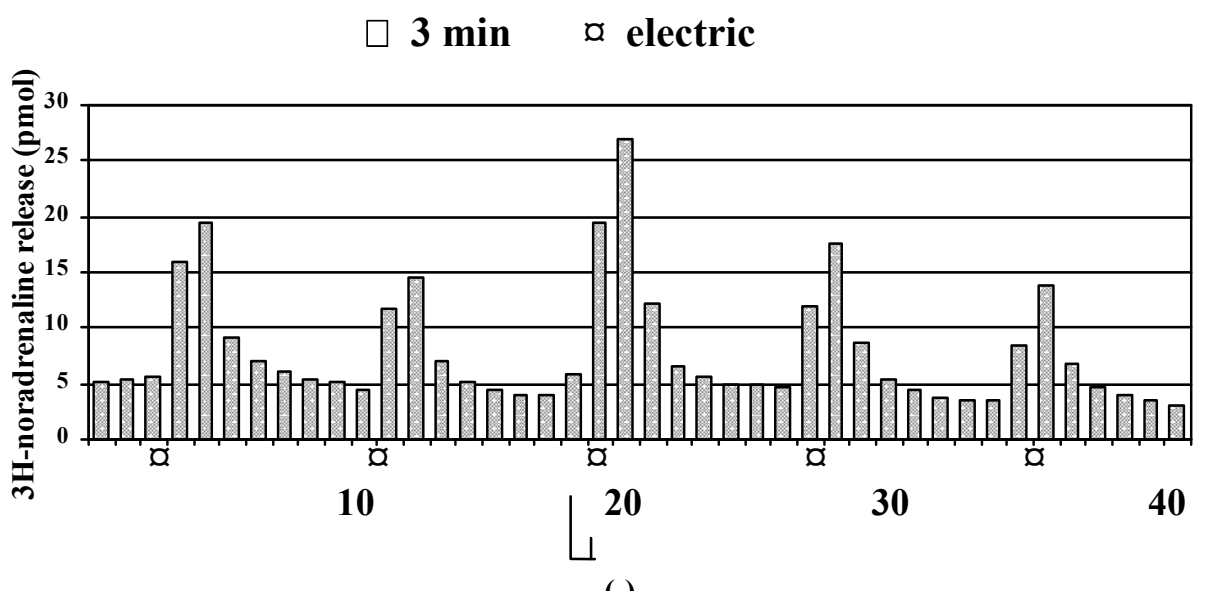

$(-)-$

DEPRENYL

(b)

Fig. 2. a. Release of $3[\mathrm{H}]$-noradrenaline from an isolated rat brain stem to consecutive electrical stimulations. There is a slow decline in response due to the exhaustion of the isolated organ. $b$ The demonstration that since $\mathrm{D}$ is devoid of the spontaneous releasing effect of $3[\mathrm{H}]$-noradrenaline characteristic to amphetamines, the CAE effect of $\mathrm{D}$, the powerful enhancement of the release of ${ }^{3}[\mathrm{H}]$-noradrenaline to electrical stimulation, is detectable. 


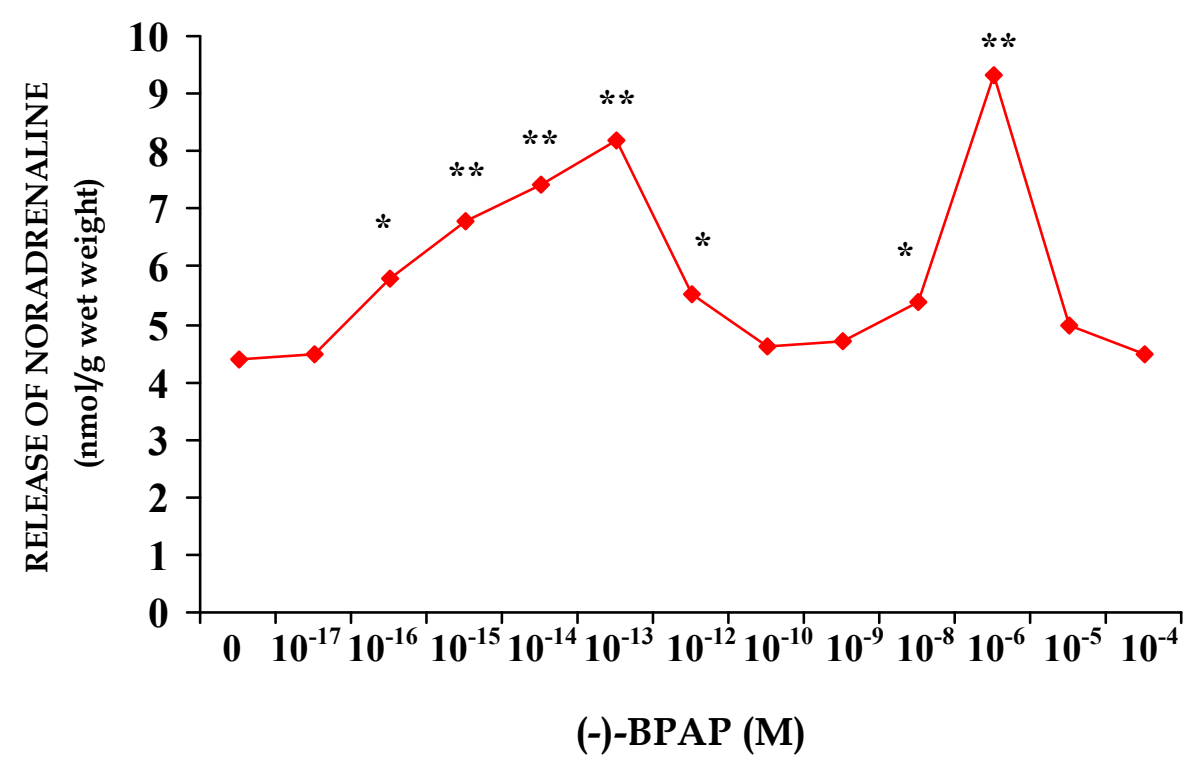

Fig. 3. The concentration effect curve characteristic to the CAE effect of enhancer substances. (The enhancer effect of BPAP on isolated locus coeruleus of rats is shown. For details see Knoll et al., 2002.); ${ }^{*} \mathrm{p}<0.01,{ }^{* *} \mathrm{p}<0.001$.

D-treatment protected completely the striatum from the toxic effect of 6-OHDA. The s.c. injection of $0.25 \mathrm{mg} / \mathrm{kg}$ D for 3 weeks and the administration of 6-OHDA 24 hours after the last injection of D did not change the ouabain-induced release of ACh. Regarding the mechanism of this protection, Knoll concluded: “...the blockade of B-type MAO, the inhibition of the uptake of 6-OHDA into the neuron and the facilitation of scavenger function, the improvement of the removal of the neurotoxic free radicals may have shares in the highly efficient shielding effect of (-)-deprenyl" (Knoll, 1987, p 57). It was shown later that D increases dopamine transporter (DAT) expression but the new DAT molecules appear not to be functionally active (Lamensdorf et al., 1999).

After this conclusion, it was a reasonable step forward to test the effect of D on the scavenger mechanism in the striatum. And we really find in Knoll's next paper the first data showing that daily administration of $\mathrm{D}$ for three weeks is significantly enhancing the activity of superoxide dismutase (SOD) in the striatum of both male and female rats (Knoll, 1988, Table VII). This was an important discovery. The finding was soon confirmed by Carrillo et al. who found that also catalase activity was induced by D (Carrillo et al., 1991).

Knoll showed that D has no direct effect on brain SOD activity in general. Using the cerebellum as a reference tissue, he showed that SOD activity in this area did not change in a statistically significant manner in D-treated male and female rats (Knoll, 1989). Carrillo et al. confirmed also this finding. They showed in rats that activities of both SOD and catalase were significantly increased in striatum and substantia nigra but not in hippocampus, 
cerebellum and liver (Carrillo et al., 1992a). They also demonstrated that in old male mice D increased SOD and catalase activities in the substantia nigra, striatum and cerebral cortex, but not in hippocampus, cerebellum or liver (Carrillo et al., 1994a). Furthermore, in accordance with the finding in rats, D increased SOD activity in the striatum, but not in the hippocampus of beagle dogs (Carrillo et al., 1994b). Knoll demonstrated that D-induced enhancement of the SOD activity in the striatum of CFY rats was unrelated to the MAO inhibitory effect of the drug. Clorgyline, one of the most potent MAO inhibitors, inhibited rather than enhanced striatal SOD activity in rats (Knoll, 1988, 1990).

As we discussed earlier, the peculiar dose-dependency of the CAE effect of the enhancer substances (see Fig.3) clearly indicates the need of special caution regarding the optimal dosage with respect to each effect of $\mathrm{D}$ and other enhancer substances. Regarding the scavenger function of D, Carrillo et al. studied in detail the sex and age-dependency on the optimal dosage of this effect in rats (Carrillo et al., 1992b, 1993). The perplexed problem of the optimal dosage of D for increasing lifespan was analyzed and discussed between 1994 (Carrillo et al., 1994c) and 2006 (Kitani et.al., 2006) in a dozen of papers.

\section{Neuroprotective effect of deprenyl}

Hundreds of experimental studies prove that D protects against a couple of toxins (MPTP, 6OHDA, DSP-4, AF64-A) and is a highly potent neuroprotective agent. The first study showing that D reduces PC12 cell apoptosis by inducing new protein synthesis was published by Tatton et al. (1994). Since this effect was exerted in concentrations as low as $10^{-13} \mathrm{M}$ it was clear that the neuroprotective effect of $\mathrm{D}$ is unrelated to MAO-B inhibition (Tatton, et al. 1996). The real unanswered question is the mechanism through which $D$ is protecting so many different cells against diverse deleterious effects. Knoll's arguments in support of the assumption that the CAE effect of $\mathrm{D}$ might be primarily responsible for most of the beneficial therapeutic effects of the drug (Knoll, 1998) require much thought. As a matter of fact, Tatton's finding was already prima-facie experimental evidence supporting Knoll's concept. D reduced PC12 cell apoptosis in $10^{-13} \mathrm{M}$ concentration, exactly in the range where D exerts its CAE effect. The final proof, however, of the key importance of the enhancer effect in the neuroprotective capacity of the enhancer substances was the development of (-)-BPAP, a more potent enhancer substance than $\mathrm{D}$ which has no chemical similarity to the propargylamines. In the first paper which described the pharmacological profile of this new experimental tool, the relation of the neuroprotective property of this compound to its enhancer effect was demonstrated (Knoll et al., 1999). In this study the protective effect of racemic BPAP was measured against $\beta$-amyloid induced neurotoxicity on cultured rat hippocampal neurons, showing that enhancer substances might favorable influence AD.

At the $10^{\text {th }}$ day the cultured cells were injured by exposing them for 3 days to a $20 \mu \mathrm{M}$ concentration of $\beta$-amyloid 25-35 fragment. This concentration of $\beta$-amyloid decreased the survival of the neurons (control $=100 \%$ ) to $22.4 \pm 7.20 \%$ (mean \pm S.D.). BPAP significantly inhibited the $\beta$-amyloid induced neurotoxicity in the cultured hippocampal neurons in two distinct ranges of concentration, one with a peak of $10^{-14} \mathrm{M}$ and one with a peak of $10^{-8} \mathrm{M}$. The peculiar concentration dependency of the effect of BPAP on the hippocampal neurons was surprisingly identical with that on the noradrenergic neurons, showing that the cell device in service of the enhancer regulation might be very similar to each other in the different enhancer-sensitive neurons (see Knoll 2001, Fig 13 and 14). 
The interpretation of the finding in the first paper describing the pharmacology of (-)-BPAP (Knoll et al., 1999, p 1731) needs still serious consideration: "As a matter of fact there is a conspicuous similarity between the BPAP induced effect on the cultured rat hippocampal neurons and the one induced by (-)deprenyl in rats treated with the drug for years during their post-developmental phase of life. In the (-)deprenyl experiment we picked out of a population of 1600 rats the animals with the lowest and the highest sexual performance and demonstrated, on the one hand, that the 'high performing' rats lived significantly longer than their 'low performing' peers, and on the other hand, that (-)deprenyl treatment transformed the low performing rats into significantly higher performing ones, which lived then as long as their saline treated high performing peers (Knoll et al., 1994). We assume that high performing, longer living rats possess a more efficient catecholaminergic brain machinery than their low performing peers and the treatment with (-)deprenyl, a CAE substance, acts accordingly. Whatever performance we measure in a random population, we always find a huge variation in efficiency, ranging from very low to very high performing individuals. This is true also regarding the performance of cells in a population of cultured neurons. We may look at the $20 \%$ of the cultured hippocampal neurons which survived in the presence of $\beta$-amyloid, as 'high performing' cells, those possessing the most efficient BPAP-sensitive activation mechanism. Adding to the cultured neurons BPAP in the optimum concentration $\left(10^{-14} \mathrm{M}\right)$, the highly potent and selective enhancer of this regulation made each neuron higher performing and the surviving rate increased from $20 \%$ to $70 \%$.

$\mathrm{BPAP}$ has obviously the same effect on the noradrenergic, dopaminergic, serotoninergic and hippocampal neurons. It may stimulate endogenous substances which enhance the activity of the neurons according to their physiological need. The high potency of BPAP in stimulating this regulation makes search in the brain after much more potent endogenous 'enhancer' substances than PEA and tryptamine, reasonable".

Hundreds of papers were published on the diverse effects of $D$, among them unexpected ones, like for example antitumor effect (ThyagaRajan \& Felten, 2002), peculiar influence on stem cells (Esmaeili et al., 2006), enhancement of the secretion of the neurotrophic factors (Ohta et al., 2002; Shimazu et al., 2003), etc. It is the most important to decide which effect of the drug is primarily responsible for the verified benefits in $\mathrm{PD}, \mathrm{AD}$, major depression, and for its antiaging effect. Since the CAE effect of D is still not common knowledge, authors may remain inattentive to their findings which give clear information about this mechanism. An example: Groc et al. (2000) presented evidence of D insensitive apoptosis of nigral neurons during development. They found that apoptotic death of dopamine neurons during development is insensitive to daily treatment of the pregnant mothers and then newborns with D $0.1,1.0$, or $10 \mathrm{mg} / \mathrm{kg}$. This finding informs about the key importance of the enhancer regulation in the effectiveness of D. Since the enhancer regulation in the brain of rats starts working only at the discontinuation of breast feeding (end of the third week of age) (Knoll \& Miklya, 1995),it is obvious that apoptotic death of nigral neurons is insensitive to daily treatment of $\mathrm{D}$ before that age.

A second example: Ohta et al. (2002) studied the effects of BPAP, the newly developed enhancer substance, on cultured mouse astrocytes, measuring one of their specific functions the secretion of neurotrophins. They found that astrocytes treated for 24 hours with $0.35 \mathrm{mM}$ BPAP secreted into the culture medium 120, 2 and 7 times more NGF, BDNF and GDNF, respectively, than the untreated (control) cells. As Fig.3 demonstrates, BPAP exerts a specific enhancer effect in picomolar concentrations and a nonspecific one in micromolar 
concentration. Since Ohta et al. investigated the effect of BPAP in high concentration only and because it is well-known that neuroglial cells play an important physiological role in the brain and modulate the function of neurons in a complex manner, but do not participate in the modification of behavioral functions, whereas BPAP is in the low pico/nanomolar concentration range influencing behavior, Knoll performed with coworkers a second study, testing BPAP on cultured mouse astrocytes in a range of $10^{-15} \mathrm{M}$ to $5 \times 10^{-4} \mathrm{M}$ concentration. This study corroborated the finding of the first one. The synthesis of NGF was significantly enhanced in the high micromolar concentration range with a peak effect at $10^{-4} \mathrm{M}$ concentration, whereas $5 \times 10^{-4} \mathrm{M}$ was ineffective. BPAP acted similarly on the synthesis of BDNF and GDNF. But the crucial step forward was the proof that, as expected, BPAP was ineffective in the low concentration range. Thus the specific form of enhancer regulation was not detectable in glial cells (Shimazu et al., 2003).

It can be little doubt that to differentiate between the specific and nonspecific enhancer effect of D requires consideration. Nevertheless, it remains for the future to identify the specific macromolecular target(s) that accommodate the endogenous enhancer substances and their synthetic derivatives; to demonstrate the existence of the predicted endogenous enhancer substances that are much more potent than PEA or tryptamine; and to map the enhancer-sensitive neurons and other cells in the brain, even if we know that the neurons of the catecholaminergic and serotonergic systems in the brain are probably the physiologically, biochemically, and pharmacologically best studied constituents of the CNS.

For the time being it is unpredictable how many enhancer sensitive-cells exist the activity of which can be influenced by enhancer substances. An example: Denes et al. (2006) demonstrated that like the widely investigated rat PC12 cells, also human brain capillary endothelial cells (HBEC) are enhancer sensitive ones. Both D and BPAP exerted their significant cytoprotective effect on both HBEC and rat PC12 cells with the dose-dependency characteristic to the enhancer substances.

\section{The rational of Knoll's concept that prophylactic deprenyl therapy may decrease the prevalence of neurodegenerative diseases, like Parkinson's and Alzheimer's}

The dopaminergic system the neurons of which originate in the substantia nigra pars compacta, ventral tegmental area and hypothalamus is influencing many important brain functions playing a key role in the ability of the human brain to acquire new behavior. According to present knowledge the nigrostriatal dopaminergic neurons are the most rapidly aging neurons in the human brain. The dopamine content of the human caudate nucleus decreases steeply, at a rate of $13-15 \%$ per decade over age 45 . We know that symptoms of PD appear if the dopamine content of the caudate sinks below $30 \%$ of the normal level. Aging of the nigrostriatal dopaminergic neurons is essentially similar in rodents and in humans. Direct biochemical evidence for the age-related decline of the dopaminergic function in rat is the loss of striatal D2-receptors in the aging brain.

Dopamine itself might play a main role in the unusually drastic age-related changes of the nigral dopaminergic system. $80 \%$ of brain dopamine is localized here. The complex autooxidation of the large amounts of DOPA and dopamine in the striatum continuously generating substantial quantities of toxic free radicals and highly reactive quinones, creates a permanent danger for the nigrostriatal dopaminergic neuron, which has to mobilize its natural defensive measures against these toxic metabolites. Neuromelanin, which is 
synthesized via the polymerization of oxidative products of dopamine, with the evident aim of finally depositing waste products, is in the substantia nigra the visible sign of successful self defense of the neuron against the free radicals and quinones originating from dopamine metabolism. The sluggish depositing of neuromelanin in the human substantia nigra is in excellent agreement with this view.

Knoll and his coworkers found that small dose D treatment prevented in rats age-related morphological changes in the neurons of the substantia nigra (Knoll et al., 1992b). This experimental study was in harmony with the clinical experience of Rinne et al. (1991) who found that the number of medial nigral neurons was greater and the number of Lewy bodies fewer in those PD patients who had been treated with D in combination with levodopa when compared with patients who had received levodopa alone. Collating the human data with the results of Knoll et al.'s study in rats it is reasonable to assume that D-treatment retards the death of the nigral neurons in the patients.

It is evident that if we focus our attention in our fight against the manifestation of PD via protecting the age-related decay of the dopaminergic machinery in the brain, we must not forget that the prophylactic low dose administration of D is strongly enhancing also the noradrenergic neurons. D and BPAP are highly potent stimulants of the noradrenergic system (Knoll, 2005). Fig.3 shows as an example that BPAP is enhancing the release of $3[\mathrm{H}]-$ noradrenaline from the isolated locus coeruleus in picomolar concentration and D acts similarly (see Fig.2b). Thus, it is of significant importance to follow those experimental and clinical studies which call attention to an inverse relationship between brain noradrenaline level and dopamine loss in PD (Tong et al., 2006). Zarow et al. (2003) showed in a study that in $\mathrm{AD}$ and $\mathrm{PD}$ neuronal loss in the locus coeruleus is greater than in substantia nigra. Locus coeruleus is a neuromelanin-pigmented neuronal structure (Ararat et al., 1977) and it is known that in PD and AD morphological alterations of the noradrenergic neurons result in a decrease of the neuronal population and this plays a role in depression and dementia in PD (Chan-Palay, 1991). A more recent study described the morphological and morphometric alterations of the locus coeruleus in patients who suffered from PD with normal cognitive function and in patients who suffered from PD associated with dementia, comparing them with normal controls and the morphological alterations of the synapses in cases of PD associated with dementia plead in favor of the importance of the normal circuits of locus coeruleus in cognitive functions (Baloyannis et al., 2006). Furthermore, it was shown that among 20 brain areas dopamine loss in PD was negatively correlated with healthy noradrenaline levels, with regions rich in noradrenaline spared from dopamine loss. The authors concluded that "...therapeutic approaches designed to enhance brain noradrenergic activity ... should be considered as possible neuroprotective strategies in PD" (Tong et al., 2006, p. 1727). Thus, the fact that D is a potent enhancer of the noradrenergic neurons is additional important factor which might substantially contribute in slowing the age-related decline of brain functions.

Since on isolated substantia nigra of rats the special CAE effect of D is detectable already at $10^{-14} \mathrm{M}$ concentration and in in vivo experiments $0.025 \mathrm{mg} / \mathrm{kg} \mathrm{D}\left(1 / 10^{\text {th }}\right.$ of the dose which blocks MAO-B) is sufficient to keep the dopaminergic neurons in the midbrain on a higher activity level, and since decades of clinical experiences showed that the regular daily dose, $10 \mathrm{mg} \mathrm{D}$ is very safe, the prophylactic administration of $1 \mathrm{mg} \mathrm{D}$ per day lends itself particularly well for life-long treatment. 


\section{Conclusion}

The catecholaminergic machinery, the noradrenergic and dopaminergic neuronal system in the brain plays a key role in the maintenance of vigilance, motivation, alerting and orientation, as well as in learning, sexual activity, drive motivated behavioral performances, cognition, etc. The dopaminergic system is the most rapidly aging neuronal system in the brain. Since the diagnosis of PD is the unequivocal proof that age-related irreversible deterioration of the nigrostriatal dopaminergic neuronal system has already surpassed a critical level in the patient, and the disease is incurable, prevention remains the only chance for the future to fight off PD.

The development of $\mathrm{D}$ in 1964/1965 which became famous in 1971/1972 as the first selective inhibitor of MAO-B and started its carrier as a therapeutic agent in 1977 as the unique MAO$B$ inhibitor which being free of the cheese effect could safely be combined with levodopa in $\mathrm{PD}$ and is at present registered in 64 countries and used to treat PD, AD and major depression, is a unique stimulant of catecholaminergic neurons in the brain. $\mathrm{D}$ is a derivative of methamphetamine, which is a long acting variant of PEA, the natural brain constituent. Both PEA and methamphetamine are known to act as releasers of catecholamines from their neuronal pool. D is the first PEA/methamphetamine-derivative free of the catecholamine releasing property and this change in the pharmacological spectrum ensured to discover that $\mathrm{D}$ is enhancing via a previously undetected mechanism the activity of the catecholaminergic neurons in the brain. This CAE effect of PEA which is exerted in much lower concentration than its catecholamine releasing effect remained undetected because the releasing effect hindered its detectability.

The role of $\mathrm{D}$ in the discovery of the enhancer regulation was clarified in a monograph (Knoll, 2005). Data were presented showing that in the course of developmental longevity, from weaning until sexual maturity, a significantly higher level of enhancer regulation is operating in the catecholaminergic neurons. This mechanism is responsible for the exuberant physical strength and mental vigor in the uphill period of life. Sexual hormones terminate this period and bring back the enhancer regulation to the pre-weaning level. This mechanism terminates developmental longevity and constitutes the foundation of the transition from adolescence to adulthood. The postdevelopmental phase of life, the slow continuous aging process, the unfortunate common fate of all mature adults begins and is finally terminated by natural death. Since D as a safe CAE substance works against the slow age-related decline of the catecholaminergic neurons in the brain, prophylactic lifelong administration of $1 \mathrm{mg} \mathrm{D}$ per day is proposed to slow the natural aging process.

The longevity studies performed with $\mathrm{D}$ furnished unequivocal evidence that life-long prophylactic treatment with $\mathrm{D}$ slowed significantly the age-related decline of the sexual performance and learning ability of animals and prolong their life. Furthermore, on the one hand, the retrospective analysis of the survival of patients treated with madopar alone $(\mathrm{N}=377)$ and with madopar plus $\mathrm{D}(\mathrm{N}=564)$ showed that the supplementation of madopar with D significantly prolonged the survival of patients, and on the other hand, the DATATOP study showed that D-treatment slowed down the rate of deterioration of the human striatal dopaminergic system. These experimental and clinical findings guide the way for the long overdue study to select at least 60 year-old healthy males and females, treat half of the population with placebo and half with $1 \mathrm{mg} D$ per day, and follow carefully the changes in their state of health until death. Since the decay of the catecholaminergic machinery with the passing of time plays an obviously important role in brain aging, and 
there is unequivocal evidence that D slows the aging of the catecholaminergic system, prophylactic D-treatment will not only improve the quality of life in senescence but it seems to be a pharmacologically well-founded expectation that the prevalence of $\mathrm{PD}$ and $\mathrm{AD}$ might be significantly lower in the D-treated group than in the placebo-treated one. Over 60 the number of the most common age-related neurodegenerative diseases, Parkinson's and Alzheimer's, start to increase because, in a sensitive part of the population the decay of some functionally key important neuronal systems surpass a critical level (like the dopaminergic machinery in case of $\mathrm{PD}$ ), thus the maintenance of the enhancer regulation on a higher activity level may slow this process. Considering the rapid increase of the population over 65 , a collaborative implementation of the proposed clinical trial, which has a fair chance of success, is of greater importance than realized heretofore.

\section{References}

Allain, H.; Gougnard, J. \& Naukirek, H.C. (1991). Selegiline in de novo parkinsonian patients: the French selegiline multicenter trial (FSMT). Acta Neurologica Scandinavica Suppl Vol.84, No.136, pp.73-78, ISSN 0065-1427

Amsterdam, J.D. (2003). A double-blind, placebo-controlled trial of the safety and efficacy of selegiline transdermal system without dietary restrictions in patients with major depressive disorder. Journal of Clinical Psychiatry Vol.64, No.2, (February 2003), pp. 208-214, ISSN 0160-6689

Ararat, D. \& Shinnamon, H. (1977). The locus coeruleus: neurobiology of a central noradrenergic nucleus. Progress in Neurobiology Vol.9, pp.147-196

Archer, J.R. \& Harrison, D.E. (1996). L-Deprenyl treatment in aged mice slightly increases life spans, and greatly reduces fecundity by aged males. Journal of Gerontology Series A - Biological Sciences and Medical Vol.51, No.6 (November 1996) pp. B448-B453, ISSN 1079-5006

Baloyannis, S.J.; Costa, V. \& Baloyannis, V.C. (2006). Morphological alterations of the synapses in the locus coeruleus in Parkinson's disease. Journal of the Neurological Sciences Vol.248, No.1-2, (October 2006) pp. 35-41,

Birkmayer, W. \& Hornykiewicz, O. (1962). Der L-dioxyphenyl-alanin-effekt beim Parkinson syndrom des Menschen. Archiv für Psychiatrie und Nervenkrankheiten Vereinigt mit Zeitschrift für die Gesamte Neurologie und Psychiatrie Vol.203, No.5, pp. 560-574, ISSN 0003-9373

Birkmayer, W.; Riederer, P., Ambrozi, L. \& Youdim, M.B.H. (1977). Implications of combined treatment with "Madopar" and L-Deprenil in Parkinson's disease. A long term study. Lancet Vol.1, No.8009, (February 1977) pp. 439-443, ISSN 0140-6736

Birkmayer, W.; Knoll, J., Riederer, P. \& Youdim, M.B.H. (1983). (-)Deprenyl leads to prolongation of 1-dopa efficacy in Parkinson's disease. Modern Problems of Pharmacopsychiatry Vol.19, pp. 170-176, ISSN 0077-0094

Birkmayer, W.; Riederer, P., Linauer, W. \& Knoll, J. (1984). L-Deprenyl plus L-phenylalanine in the treatment of depression. Journal of Neural Transmission-General Section Vol.59, No.1, pp. 81-87, ISSN 0300-9564

Birkmayer, W.; Knoll, J., Riederer, P., Youdim, M.B.H., Hars, V. \& Marton, V. (1985). Increased life expectancy resulting from addition of L-deprenyl to Madopar treatment in Parkinson's disease: a longterm study. Journal of Neural TransmissionGeneral Section Vol.64, No.2, pp. 113-127, ISSN 0300-9564 
Blackwell, B. (1963). Hypertensive crisis due to monoamine oxidase inhibitors. The Lancet Vol.282, No.7313, pp. 849-851, ISSN 0140-6736

Carrillo, M.C.; Kanai, S., Nokubo, M. \& Kitani, K. (1991). (-)-Deprenyl induces activities of both superoxide dismutase and catalase but not of glutathione peroxidase in striatum of young male rats. Life Sciences Vol.48, No.6, pp. 517-521, ISSN 0024-3205

Carrillo, M.C.; Kitani, K., Kanai, S. \& Ivy, G.O. (1992a). The ability of (-)-deprenyl to increase superoxide dismutase activities in the rat is tissue and brain region selective. Life Sciences Vol.50, No.25, pp. 1985-1992, ISSN 0024-3205

Carrillo, M.C.; Kanai, S., Nokubo, M., Ivy, G.O., Sato, Y. \& Kitani, K. (1992b). (-)-Deprenyl increases activities of superoxide dismutase and catalase in striatum but not in hippocampus: the sex and age-related differences in optimal dose in the rat. Experimental Neurology Vol.116, No.3, pp. 286-294, ISSN 0014-4886

Carrillo, M.C.; Kanai, S., Sato, Y., Nokubo, M., Ivy, G.O. \& Kitani, K. (1993). The optimal dosage of (-)deprenyl for increasing superoxidase dismutase activities in several brain regions decreases with age in male Fischer 344 rats. Life Sciences Vol.52, No.24, pp. 1925-1934, ISSN 0024-3205

Carrillo, M.C.; Kitani, K., Kanai, S., Sato, Y., Miyasaka, K. \& Ivy, G.O. (1994a). (-)-Deprenyl increases activities of superoxide dismutase and catalase in certain brain regions in old male mice. Life Sciences Vol.54, No.14, pp. 975-981, ISSN 0024-3205

Carrillo, M.C.; Ivy, G.O., Milgram, N.W., Head, E., Wu, P. \& Kitani, K. (1994b). (-)Deprenyl increases activities of superoxide dismutase (SOD) in striatum of dog brain. Life Sciences Vol.54, No.20, pp. 1483-1489, ISSN 0024-3205

Carrillo, M.C.; Kitani, K., Kanai, S., Sato, Y., Miyasaka, K. \& Ivy, G.O. (1994c). The effect of long term (6 months) treatment with (-)deprenyl on antioxidant enzyme activities in selective brain regions in old female Fischer 344 rats. Biochemical Pharmacology Vol.47, No.8, pp. 1333-1338, ISSN 0006-2952

Chan-Palay, V. (1991). Depression and dementia in Parkinson's disease: catecholamine changes in the locus coeruleus - Basis for therapy. Dementia Vol.2, No.1, pp. 7-17, ISSN 1013-7424

Crane, G.E. (1956). Psychiatric side effects of iproniazid. The American Journal of Psychiatry Vol.112, No.7, pp. 494-501

Esmaeili, F.; Tiraihi, T., Movahedin, M. \& Mowla, S.J. (2006). Selegiline induces neuronal phenotype and neurotrophins expression in embryonic stem cells. Rejuvenation Research Vol.9, No.4 (Winter, 2006) pp 475-484, ISSN 1549-1684

Freisleben, H.J.; Lehr, F. \& Fuchs, J. (1994) Lifespan of immunosuppressed NMRI-mice is increased by deprenyl. Journal Neural Transmission Supplement Vol.41, pp. 231-236, ISSN 0303-6965

Gallagher, I.M.; Clow, A. \& Glover, V. (1998). Long term administration of (-)deprenyl increases mortality in male Wistar rats. Journal of Neural Transmission Supplement No.52, pp. 315-320, ISSN 0303-6995

Gaszner, P. \& Miklya, I. (2006). Major depression and the synthetic enhancer substances, (-)-deprenyl and R-(-)-1-(benzofuran-2-yl)-2-propylaminopentane. Progress in Neuro-Psychopharmacology Biological Psychiatry Vol.30, No.1, pp. 5-14, ISSN 027785846

Groc, L.; Levine, R.A., Foster, J.A., Normile, H.J., Weissmann, D. \& Bezin, L. (2000). Evidence of deprenyl-insensitive apoptosis of nigral dopamine neurons during development. Developmental Brain Research Vol.120, No.1, pp. 95-98, ISSN 0165-3806 
Hall, D.W.R.; Logan, B.W. \& Parsons, G.H. (1969). Further studies on the inhibition of monoamine oxydase by MB 9302 (clorgyline)-I. Substrate specificity in various mammalians species. Biochemical Pharmacology Vol.18, No.6, pp. 1447-1454, ISSN 0006-2952

Johnston, J.P. (1968). Some observations upon a new inhibitor of monoamine oxidase in human brain. Biochemical Pharmacology Vol.17, No.7, pp. 1285-1297, ISSN 0006-2952

Ingram, D.K.; Wiener, H.L., Chachich, M.E., Longo, J.M., Hengemihle, J. \& Gupta, M. (1993). Chronic treatment of aged mice with L-deprenyl produced marked MAO-B inhibition but no beneficial effects on survival, motor performance, or nigral lipofuscin accumulation. Neurobiology of Aging Vol.14, No.5, pp. 431-440, ISSN 01974580

Kitani, K.; Kanai, S., Sato, Y., Ohta, M., Ivy, G.O. \& Carrillo, M.C. (1993). Chronic treatment of (-)deprenyl prolongs the life span of male Fischer 344 rats. Further evidence. Life Sciences Vol.52, No.3, pp. 281-288, ISSN0024-3205

Kitani, K.; Kanai, S., Miyasaka, K., Carrillo, M.C. \& Ivy, G.O. (2006). The necessity of having a proper dose of (-)deprenyl (D) to prolong the life spans of rats explains discrepancies among different studies in the past. Annals of the New York Academy of Sciences Vol.1067, No.1, pp. 375-382, ISSN 0077-8923

Kline, N.S. (1958). Clinical experience with iproniazid (marsilid). Journal of Clinical Experimental Psychophathology Supplement 1, Vol.19, pp. 72-78

Knoll, J. (1976). Analysis of the pharmacological effects of selective monoamine oxidase inhibitors. In: Monoamine oxidase and its inhibition. Ciba Foundation Symposium 39 (new series), G.E.S. Wolstenholme \& J. Knight, (Eds), pp. 131-161, ISBN 0444-15259, Elsevier, Amsterdam

Knoll, J. (1978a). On the dual nature monoamine oxidase. Horizons in Biochemistry and Biophysics Vol.5, pp. 37-64

Knoll, J. (1978b). The possible mechanism of action of (-)deprenyl in Parkinson's disease. Journal of Neural Transmission - General Section Vol.43, No.3-4, pp. 177-198

Knoll, J. (1978c). The pharmacology of selective irreversible monoamine oxidase inhibitors. In: Enzyme-activated irreversible inhibitors, N. Seiler, M.J. Jung \& J. Koch-Weser, (Eds), pp 253-269, ISBN 0-444-80080-8, Elsevier/North Holland

Knoll, J. (1981a). Can the suicide inactivation of MAO by deprenyl explain its pharmacological effects? In: Molecular Basis of Drug Action, T. Singer \& N. Ondarza, (Eds), pp 185-201, ISBN 0-444-00632-X, Elsevier, Amsterdam

Knoll, J. (1981b). The pharmacology of selective MAO inhibitors. In: Monoamine Oxidase Inhibitors. The State of the Art, M.B.H. Youdim \& E.S. Paykel, (Eds), pp 45-61, Wiley, New York

Knoll, J. (1982). Selective inhibition of B type monoamine oxidase in the brain: a drug strategy to improve the quality of life in senescence. In: Strategy in Drug Research, J.A. Keverling Buisman, (Ed), pp 107-135, ISBN 0-444-42053-3, Elsevier, Amsterdam

Knoll, J. (1983). Deprenyl (selegiline). The history of its development and pharmacological action. Acta Neurolologica Scandinavica Vol.68, Suppl 95, pp. 57-80, ISSN 0001-6314

Knoll, J. (1985). The facilitation of dopaminergic activity in the aged brain by (-)deprenyl. A proposal for a strategy to improve the quality of life in senescence. Mechanisms of Ageing and Development Vol.30, No.2, pp.109-122, ISSN 0047-6374 
Knoll, J. (1987). R-(-)Deprenyl (Selegiline, Movergan R) facilitates the activity of the nigrostriatal dopaminergic neuron. Journal of Neural Transmission Supplement 25, pp. 45-66, ISSN 0303-6965

Knoll, J. (1988). The striatal dopamine dependency of lifespan in male rats. Longevity study with (-)deprenyl. Mechanisms of Ageing and Development Vol.46, No.1-3, pp. 237-262, ISSN 0047-6374

Knoll, J. (1989). The pharmacology of selegiline /(-)deprenyl/. New aspects. Acta Neurologica Scandinavica Supplement 80, No.126, pp. 83-91, ISSN 0065-1427

Knoll, J. (1990). Nigrostriatal dopaminerg activity, deprenyl treatment, and longevity. In: Advances in Neurology.Vol. 53: Parkinson's disease: anatomy, pathology, and therapy..: M.M. Streifler, A.D. Korczyn, E. Melamed \& M.H.B. Youdim, (Eds), pp 425-429, ISSN 0091-3952, Raven Press, New York

Knoll, J. (1992). Pharmacological basis of the therapeutic effect of (-)deprenyl in age-related neurological diseases. Medicinal Research Reviews Vol.12, No.5, pp. 505-524, ISSN 0198-6325

Knoll, J. (1994). Memories of my 45 years in research. Pharmacology \& Toxicology Vol.75, No.2, pp. 65-72, ISSN 0901-9928

Knoll, J. (1998). (-)Deprenyl (Selegiline), a catecholaminergic activity enhancer (CAE) substance acting in the brain. Pharmacology \& Toxicology Vol.82, No.2, pp. 57-66, ISSN 0901-9928

Knoll, J. (2001). Antiaging compounds: (-)Deprenyl (Selegiline) and (-)1-(benzofuran-2-yl)-2propylaminopentane, (-)BPAP, a selective highly potent enhancer of the impulse propagation mediated release of catecholamines and serotonin in the brain. CNS Drug Reviews Vol.7, No.3, pp. 317-345, ISSN 1080-563X

Knoll, J. (2005). The brain and its self. A neurochemical concept of the innate and acquired drives. ISBN -10 3-540-23969-3, Springer, Berlin, Heidelberg, New York.

Knoll, J. \& Magyar, K. (1972). Some puzzling effects of monoamine oxidase inhibitors. Advances in Biochemical Psychopharmacology Vol.5, pp. 393-408

Knoll, J. \& Miklya, I. (1994). Multiple small dose administration of (-)deprenyl enhances catecholaminergic activity and diminishes serotonergic activity in the brain and these effects are unrelated to MAO-B inhibition. Archives Internationales de Pharmacodynamie et de Therapie Vol.328, No.1, pp. 1-15, ISSN 0003-9780

Knoll, J. \& Miklya, I. (1995). Enchanced catecholaminergic and serotoninergic activity in rat brain from weaning to sexual maturity: Rationale for prophylactic (-) deprenyl (selegiline) medication. Life Sciences Vol.56, No.8, pp. 611-620, ISSN 0024-3205

Knoll, J.; Ecseri, Z., Kelemen, K., Nievel, J. \& Knoll, B. (1965). Phenylisopropylmethyl propinylamine (E-250) a new psychic energizer. Archives Internationales de Pharmacodynamie et de Thérapie Vol.155, No.1, pp. 154-164, ISSN 0003-9780

Knoll, J.; Vizi, E.S. \& Somogyi, G. (1968). Phenylisopropylmethylpropinylamine (E-250), a monoamine oxidase inhibitor antagonizing the effects of tyramine. Arzneimittelforschung Vol.18, pp. 109-112

Knoll, J.; Yen, T.T. \& Dallo, J. (1983). Long-lasting, true aphrodisiac affect of (-)deprenyl in sexually sluggish old male rats. Modern Problems of Pharmacopsychiatry Vol.19, pp. 135-153, ISSN 0077-0094

Knoll, J.; Dallo, J. \& Yen, T.T. (1989). Striatal dopamine, sexual activity and lifespan. Longevity of rats treated with (-)deprenyl. Life Sciences Vol.45, No.6, pp. 525-531, ISSN 0024-3205 
Knoll, J.; Knoll, B., Török, Z., Timar, J. \& Yasar, S. (1992a). The pharmacology of 1-phenyl-2propylamino-pentane (PPAP) a deprenyl-derived new spectrum psycho-stimulant. Archives Internationales de Pharmacodynamie et de Therapie Vol.316, pp. 5-29, ISSN 0003-9780

Knoll, J.; Toth, V., Kummert, M. \& Sugar, J. (1992b). (-)Deprenyl and (-)parafluorodeprenyltreatment prevents age-related pigment changes in the substantia nigra. A TVimage analysis of neuromelanin. Mechanisms of Ageing and Development Vol.63, No.2, pp. 157-163, ISSN 0047-6374

Knoll, J.; Yen, T.T. \& Miklya, I. (1994). Sexually low performing male rats dies earlier than their high performing peers and (-)deprenyl treatment eliminates this difference. Life Sciences Vol.54, No.15, pp. 1047-1057, ISSN 0024-3205

Knoll, J., Miklya, I., Knoll, B., Marko, R. \& Racz, D. (1996a). Phenylethylamine and tyramine are mixed-acting sympathomimetic amines in the brain. Life Sciences Vol.58, No.23, pp. 2101-2114, ISSN 0024-3205

Knoll, J.; Miklya, I., Knoll, B., Marko, R. \& Kelemen, K. (1996b). (-)Deprenyl and (-)1-phenyl-2-propilaminopentane, (-)PPAP, act primarly as potent stimulants of actionpotential - transmitter release coupling in the catecholaminergic neurons. Life Sciences Vol.58, No.10, pp. 817-827, ISSN 0024-3205

Knoll, J.; Yoneda, F., Knoll, B., Ohde, H. \& Miklya, I. (1999). (-)1-(Benzofuran-2-yl)-2propylaminopentane, /(-)BPAP/, a selective enhancer of the impulse propagation mediated release of catecholamines and serotonin in the brain. British Journal of Pharmacology Vol.128, No.8, pp. 1723-1732, ISSN 0007-1188

Knoll, J.; Miklya, I. \& Knoll, B. (2002). Stimulation of the catecholaminergic and serotoninergic neurons in the rat brain by R-(-)-1-(benzofuran-2-yl)-2propylaminopentane, (-)-BPAP. Life Sciences Vol.71, No.18, pp. 2137-2144, ISSN 0024-3205

Lancet Editorial. (1982). Deprenyl in Parkinson's Disease. The Lancet Vol.2, No.8300, (September 25) pp. 695-696, ISSN 0140-6736

Lamensdorf, I.; Porat, S.; Simantov, R.. \& Finberg, J.P. (1999) Effect of low-dose treatment with selegiline on dopamine transporter (DAT) expression and amphetamineinduced dopamine release in vivo. British Journal of Pharmacology Vol. 126, No.4, pp.997-1002, ISSN 0007-1188

Larsen, J.P.; Boas, J. \& Erdal, J.E. (1999). Does selegiline modify the progression of early Parkinson's disease? Results from a five-year study. The Norwegian-Danish Study Group. European Journal of Neurology Vol.6, No.5, pp. 539-547, ISSN 1351-5101

Lees, A.J. (1995). Comparison of therapeutic effects and mortality data of levodopa and levodopa combined with selegiline in patients with early, mild Parkinson's disease British Medical Journal Vol.311, No.7020, pp. 1602-1607, ISSN 0959-535X

Mann, J.J. \& Gershon, S. (1980). A selective monoamine oxidase-B inhibitor in endogenous depression. Life Sciences Vol.26, No.11, pp. 877-882, ISSN 0024-3205

Martini, E.; Pataky, I., Szilagyi, K. \& Venter, V. (1987). Brief information on an early phase-II study with (-)deprenyl in demented patients. Pharmacopsychiatry Vol.20, No.6, pp. 256-257, ISSN 0176-3679

Miklya, I. (2008). A comparison of the pharmacology of (-)-deprenyl to N-methylpropargylamine-1-aminoindane (J-508) and rasagiline, the desmethyl-analogue of J508. Neuropsychopharmacologia Hungarica Vol.10, No.1, pp. 15-22 
Milgram, M.W.; Racine, R.J., Nellis, P., Mendoca, A. \& Ivy, G.O. (1990). Maintenance on L-(-)deprenyl prolongs life in aged male rats. Life Sciences Vol.47, No.5, pp. 415-420, ISSN 0024-3205

Miyoshi, K. (2001). Parkinson's disease. Nippon Rinsho. Japanese Journal of Clinical Medicine Vol.59, No.8, pp. 1570-1573, ISSN 0047-1852

Myttyla, V.V.; Sotaniemi, K.A., Vourinen, J.A. \& Heinonen, E.H. (1992). Selegiline as initial treatment in de novo parkinsonian patiens. Neurology Vol.42, pp. 339-343

Ohta, K.; Ohta, M., Mizuta, I., Fujinami, A., Shimazu, S., Sato, N., Yoneda, F., Hayashi, K. \& Kuno, S. (2002). The novel catecholaminergic and serotonergic activity enhancer $R$-(-)-1-(benzofuran-2-yl)-2-propylaminopentane up-regulates neurotrophic factor synthesis in mouse astrocytes. Neuroscience Letters Vol.328, No.3, pp. 205-208, ISSN 0304-3940

Parkinson Study Group. (1989). Effect of (-)deprenyl on the progression disability in early Parkinson's disease. New England Journal of Medicine Vol.321, No.20, pp. 1364-1371, ISSN 0028-4793

Parkinson Study Group. (1993). Effect to tocopherol and (-)deprenyl on the progression of disability in early Parkinson's disease. New England Journal of Medicine Vol.328, No.3, pp. 176-183, ISSN 0028-4793

Rinne, J.O.; Röyttä, M., Paljärvi, L., Rummukainen, J. \& Rinne, U.K. (1991). Selegiline (deprenyl) treatment and death of nigral neurons in Parkinson's disease. Neurology Vol.41, No.6, pp. 859-861, ISSN 0028-3878

Ruehl, W.W.; Entriken, T.L., Muggenberg, B.A., Bruyette, D.S., Griffith, W.G. \& Hahn, F.F. (1997). Treatment with L-deprenyl prolongs life in elderly dogs. Life Sciences Vol.61, No.11, pp. 1037-1044, ISSN 0024-3205

Sano, M.; Ernesto, C., Thomas, R.G., Klauber, M.R., Schafer, K., Grundman, M., Woodbury, P., Growdon, J., Cotman, C.W., Pfeiffer, E., Schneider, L.S. \& Thal, L.J. (1997). A controlled trial of selegiline, alpha-tocopherol, or both as treatment for Alzheimer's disease. New England Journal of Medicine Vol.336, No.17, pp. 1216-1222, ISSN 00284793

Shimazu, S.; Tanigawa, A., Sato, N., Yoneda, F., Hayashi, K., Knoll, J. (2003). Enhancer substances: Selegiline and $R-(-)-1-($ benzofuran-2-yl)-2-propylaminopentane, [(-)BPAP] enhance the neurotrophic factor synthesis on cultured mouse astrocytes. Life Sciences Vol.72, No.24, pp. 2785-2792, ISSN 0024-3205

Stoll, S.; Hafner, U., Kranzlin, B. \& Muller, W.E. (1997). Chronic treatment of Syrian hamsters with low-dose selegiline increases life span in females but not males. Neurobiology of Aging Vol.18, Mo.2, pp. 205-211, ISSN 0197-4580

Tariot, P.N.; Cohen, R.M., Sunderland, T., Newhouse, P.A., Yount, D. \& Mellow, A.M. (1987). L-(-)Deprenyl in Alzheimer's disease. Archives of General Psychiatry Vol.44, No.5, pp. 427-433, ISSN 0003-990X

Tatton, W.G.; Ju, W.Y., Holland, D.P., Tai, C. \& Kwan, M. (1994). (-)-Deprenyl reduces PC12 cell apoptosis by inducing new protein synthesis. Journal of Neurochemistry Vol.63, No.4, pp. 1572-1575, ISSN 0022-3042

Tatton, W.G.; Wadia, J.S., Ju, W.Y., Chalmers-Redman, R.M. \& Tatton, N.A. (1996). (-)-Deprenyl reduces neuronal apoptosis and facilitates neuronal outgrowth by altering protein synthesis without inhibiting monoamine oxidase. Journal of Neural Transmission Supplement, Vol.48, pp. 45-59, ISSN 0303-6995 
Tetrud, J.W. \& Langston, J.W. (1989). The effect of (-)deprenyl (selegiline) on the natural history of Parkinson's disease. Science Vol.245, No.4917, pp. 519-522, ISSN 00368075

ThyagaRajan, S. \& Felten, D.L. (2002). Modulation of neuroendocrine-immune signaling by L-deprenyl and L-desmethyldeprenyl in aging and mammary cancer. Mechanisms Aging and Development Vol.123, No.8, (April, 2002), pp.1065-1079, ISSN 0047-6374

Tom, T. \& Cummings, J.L. (1998). Depression in Parkinson's disease. Pharmacological characteristics and treatment. Drugs Aging Vol.12, No.1, pp. 55-74, ISSN 1170-229X

Tong, J.; Hornykiewicz, O. \& Kish, S.J. (2006). Inverse relationship between brain noradrenaline level and dopamine loss in Parkinson Disease. Archives of Neurology Vol.63, No.12, pp. 1724-1728, ISSN 0003-9942

Tringer, L., Haits, G. \& Varga, E. (1971). The effect of (-)E-250, (-)L-phenyl-isopropylmethylpropinyl-amine $\mathrm{HCl}$, in depression. In: $V$. Conferentia Hungarica pro Therapia et Investigatione in Pharmacologia, G. Leszkovszky, (Ed), pp 111-114, Publishing House of the Hungarian Academy of Sciences, Budapest,

Varga, E. (1965). Vorläufiger Bericht über die Wirkung des Präparats E-250 (phenylisopropyl-methyl-propinylamine-chlorhydrat) In: III. Conferentia Hungarica pro Therapia et Investigatione in Pharmacologia, B. Dumbovich, (Ed), pp 197-201, Publishing House of the Hungarian Academy of Sciences, Budapest,

Varga, E. \& Tringer, L. (1967). Clinical trial of a new type of promptly acting psychoenergetic agent (phenyl-isopropylmethyl-propinylamine $\mathrm{HCl}, \mathrm{E}-250$ ). Acta Medica Academiae Scientiarum Hungaricae Vol.23, No.3, pp. 289-295, ISSN 0001-5989

Yasar, S.; Winger, G., Nickel, B., Schulze, G. \& Goldberg, S.R. (1993). Preclinical evaluation of 1-deprenyl: Lack of amphetamine-like abuse potential. In: Inhibitors of Monoamine Oxidase B. Pharmacology and Clinical Use in Neurodegenerative Disorders, I. Szelenyi, (Ed), pp215-233, ISBN 3-7643-2782-0, Birkhauser Verlag, Basel, Switzerland

Yen, T.T. \& Knoll, J. (1992). Extension of lifespan in mice treated with Dinh lang (Policias fruticosum L.) and (-)deprenyl. Acta Physiologica Hungarica Vol.79, No.2, pp. 119124, ISSN 0231-424X

Yen, T.T.; Dallo, J. \& Knoll, J. (1982). The aphrodisiac effect of low doses of (-)deprenyl in male rats. Polish Journal of Pharmacology and Pharmacy Vol.34, No.5-6, pp. 303-308, ISSN 0301-0244

Youdim, M.B. (1980). Monoamine oxidase inhibitors as anti-depressant drugs and as adjuct to L-dopa therapy of Parkinson's disease. Journal of Neural Transmission Supplement, Vol.16, pp. 157-161, ISSN 0303-6995

Zarow, C.; Lynnes, S.A., Mortimer, J.A. \& Chui, H.C. (2003). Neuronal loss is greater in the locus coeruleus than nucleus basalis and substantia nigra in Alzheimer and Parkinson disease. Archives of Neurology Vol.60, No.3, pp. 337-341, ISSN 0003-9942

Zeller, E.A. \& Barsky. J. (1952). In vivo inhibition of liver and brain monoamine oxidase by 1-isonicotinyl-2-isopropylhydrazine. Proceedings of the Society for Experimental Biology and Medicine Vol.81, pp. 459-468

Zesiewitz, T.A.; Gold, M,, Chari, G. \& Hauser, R.A. (1999). Current issues in depression in Parkinson's disease. The American Journal of Geriatric Psychiatry Vol.7, No.2, pp. 110118 


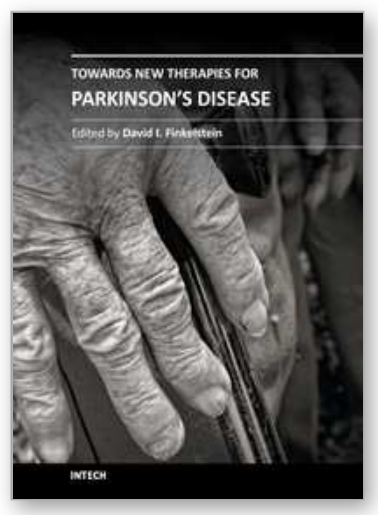

\section{Towards New Therapies for Parkinson's Disease}

Edited by Prof. David Finkelstein

ISBN 978-953-307-463-4

Hard cover, 396 pages

Publisher InTech

Published online 02, November, 2011

Published in print edition November, 2011

Parkinson's disease (PD) is characterised clinically by various non-motor and progressive motor symptoms, pathologically by loss of dopamine producing cells and intraneuronal cytoplasmic inclusions composed primarily of ?-synuclein. By the time a patient first presents with symptoms of Parkinson's disease at the clinic, a significant proportion of the cells in the substantia nigra have already been destroyed. This degeneration progresses despite the current therapies until the cell loss is so great that the quality of normal life is compromised. The dopamine precursor levodopa is the most valuable drug currently available for the treatment of PD. However for most PD patients, the optimal clinical benefit from levodopa decreases around five to six years of treatment. The aim of the chapters of this book is to work towards an understanding in the mechanisms of degeneration and to develop disease modifying therapies.

\section{How to reference}

In order to correctly reference this scholarly work, feel free to copy and paste the following:

Ildikó Miklya (2011). The Knoll-Concept to Decrease the Prevalence of Parkinson's Disease, Towards New Therapies for Parkinson's Disease, Prof. David Finkelstein (Ed.), ISBN: 978-953-307-463-4, InTech, Available from: http://www.intechopen.com/books/towards-new-therapies-for-parkinson-s-disease/the-knoll-concept-todecrease-the-prevalence-of-parkinson-s-disease

\section{INTECH}

open science | open minds

\author{
InTech Europe \\ University Campus STeP Ri \\ Slavka Krautzeka 83/A \\ 51000 Rijeka, Croatia \\ Phone: +385 (51) 770447 \\ Fax: +385 (51) 686166 \\ www.intechopen.com
}

\author{
InTech China \\ Unit 405, Office Block, Hotel Equatorial Shanghai \\ No.65, Yan An Road (West), Shanghai, 200040, China \\ 中国上海市延安西路65号上海国际贵都大饭店办公楼 405 单元 \\ Phone: +86-21-62489820 \\ Fax: +86-21-62489821
}


(C) 2011 The Author(s). Licensee IntechOpen. This is an open access article distributed under the terms of the Creative Commons Attribution 3.0 License, which permits unrestricted use, distribution, and reproduction in any medium, provided the original work is properly cited. 